\title{
Minimalist Architectural Space as a Carrier of Connotations of Social Benefits (High Quality of Life)
}

\author{
Tatyana Valentinovna Gudkova ${ }^{1}$ \\ ${ }^{1}$ Novosibirsk State Academy of Architecture and Arts, Novosibirsk, Russia \\ Correspondence: Tatyana Valentinovna Gudkova, Novosibirsk State Academy of Architecture and Arts, Krasny \\ prospekt., 38, Novosibirsk, 630099, Russia. E-mail: tatyana_v_gudkova@mail.ru
}

Received: October 1, 2014 Accepted: October 31, 2014 Online Published: November 15, 2014

doi:10.5539/res.v6n4p122 URL: http://dx.doi.org/10.5539/res.v6n4p122

\begin{abstract}
In this article, the minimalist architecture is introduced from the standpoint of consumerism, and a minimalist architectural space with its individual features, not only as a living space, but also as a carrier of connotations, demanded in a consumer society: an open space acts as a semantic association or representation of a spiritual, material, and personal freedom; closed (outside) space - as an idea about security, autonomy; single (interior) space with a minimum zoning - as a representation of life at your own pace; large space — as a connotation of wealth, prestige and status of its owner; empty interior space-as a connotation of independence from the artificial world (world of things) and consumerism.
\end{abstract}

Keywords: minimal architecture, minimalist architecture, minimalism, design, minimalist connotation in architecture, modernism, modern architecture, modern movement, consumer society, consumerism, styles, architectural reductionism, sociology of architecture

\section{Introduction}

Thanks to the incarnate ideas and manifestos of Le Corbusier and Mies van der Rohe, picked up by other architects, the Industrial Revolution, world industrialization, and scientific and technological progress became the basis for the development of modernist architecture in the 20th century.

The modernist architecture, in terms of geometry, design is reduced and formalized. The simplicity of buildings was caused to both, the new constructions (metal, reinforced concrete frame) and modern construction materials, and the new aesthetic notions of beauty, formed through the aestheticization of industrial production results.

Gradually the industrial society was replaced by the consumer society, in which a person is judged not by his beliefs, and by what he consumes. The modernist architecture, along with other products, has become the personification of global processes taking place in society, and with a total recognizability, this has acquired a number of new features. This indicates that by adapting of its ideas to the desires and demands of the consumer, other tendencies were outlined within the major modernist movement. To one of such modern tendencies you can contribute the minimalist architecture, where a genetic link with the modernist architecture can be seen.

The term minimalism appeared in the late 70s, they talked about the minimal architecture as about the existing trend in the late 80's, but the first monographs appeared in the mid-90s (Stevanovic, 2013). There are some authors, who associate it with the modernist movement, but some of them perceive the features that make such architecture related with the postmodernism and the consumer society. So, Grimshaw writes about the minimalist architecture as about the reanimated modernism by using the term "Soft Modernism" (Grimshaw, 2004), and Ilka \& Andreas Ruby call it reductionist, but at the same time refer the minimalist tendency to the consumer society (Ruby et al., 2003). Aureli notes that the ascetic restraint of this architecture is a marketing ploy of the consumer society, unrelated to the spiritual asceticism, which architects are trying to put in it (Aureli, 2014). Glancey argues that it creates a new lifestyle for the wealthy class (Glancey \& Bryant, 1998). Macarthur denotes the minimalism, as a part of broad movement of "new modernism" or "second modernism". He writes that such architecture occupied a place alongside the other products, and the neo-modernist minimalism is essentially a modernism-like, that the social context and typical user of architecture, which is "free from politics and sociology", has changed (Macarthur, 2002). Ibelings, by analyzing the architecture of minimum, in which the main slogan is "Less is more", uses the term "super-modernism", but at the same time he highlights the 
neutrality and out-contextuality of such architecture, and it also connects it with the modernism of the 20th century (Ibelings, 1998). Jencks argues that the minimalism is a bourgeois version of modernism, stressing the loss of ideological component and commercialization of spirituality (Stevanovic, 2013). In the diagram "Evolutionary Tree of 20th century architecture" he denotes the period of 1980-1990 years as a New Modernism. Jencks sees the origins of modernism in the logical tradition (LOGICAL). In this tradition Jenks also has included the minimalist tendency (Jencks, 2007).

Based on the foregoing we can state that, on the one hand, the minimalist architecture can be referred to the developing tendency within the main modernistic movement, but, on the other hand, Macarthur says that minimalism is free from social and ideological connotations of modernism and historical memory, giving him the right to be called a commodity due to the commercialization of culture in late capitalism (Macarthur, 2002), and Grimshaw - about the freedom of minimalism from the modernistic theory and the original context, linking minimalism in the architecture with the consumer society by the time of birth and formation (Grimshaw, 2004). The genetic relation with modernism and the historical relation with postmodernism create a contradictory nature of understanding of minimalist tendency. Some authors consider the minimalist architecture as a neutral and non-symbolic architecture, which can be placed anywhere in the global world. Other theorists concluded that the return of modernistic ideas into the consumer society took place. Because more authors write about minimalism in the architecture from the perspective of consumerism (Ibelings, 1998; Castillo, 2004; Grimshaw, 2004; Frampton, 2007; Stevanovic, 2013; Aureli, 2014), the following hypothesis arises: if it's equated with commodity, in order to sell it, it shall be a carrier of connotations, demanded in the consumer society. Therefore, the purpose of this article is: to identify those social benefits of the consumer society and their connotations, a carrier of which is this architecture.

\section{Research Methodology}

\subsection{Authentic Features of Minimalist Architecture}

What design preferences do the authors of this architecture use?

Bertoni opposes the building of modernist movement, opened to the environment due to the external surfaces made of glass, to the minimalist architecture, highlighting therein: isolation ("closed" architecture), lack of visible detail, implementation of natural environment into the object. The "open" minimalist architecture, according to him, is only possible in a pure natural surrounding (Bertoni, 2002).

Ilka \& Andreas Ruby, speaking of Essential Minimalism, as of the core of minimalist tendency, define "design preferences: introversion, simple geometry, smooth surfaces, absence of visible details and "authenticity" of materials" (glass, concrete, wood without coloring, technological treatment and decoration) (Ruby et al., 2003, p. 17).

The article of Stevanovic speaks of concepts of simplicity, emptiness, spirituality, existence and modesty, which are peculiar to minimalism since the beginning of its formation. To the distinctive qualities of minimalism he listed in Montaner (1993) - rigor of geometric shapes, technical accuracy, unity and simplicity, scale distortion; in Vice (1994) — reduction, simplicity, linearity, a low-key color palette; in Murray (1999)—architectural reduction of space, light, mass; in Ibelings (1998) - monolithic of shapes, light design, shape sublimation, improved technologies and new materials, absence of ideology, semantics and out-contextually; in Macarthur (2002) - absence of social and ideological connotations and historical memory; in Bertoni (2002)—reduction, expressive clarity, strict essentiality, mental purity, formal simplicity (Stevanovic, 2013).

Speaking of minimalist aesthetics, Powson stressed the importance of space: "I believe we have to get away from the idea of minimalism as a style and instead understand it as a way of thinking about space: its proportions, its surfaces, and the fall of light" (Ferdinand, 2014).

In summary, to the authentic features of minimalist architecture we can attribute 1) single, subjected to reduction, space and an outer monolithic, strict and unified shape of the building; 2) light and monochrome / neutral color; 3) emptiness, strict and simplicity, it emphasizes the importance of space inside the object and the unified unsegmented shape of the building; 4) homogeneity of surfaces and the lack of details, thus distorting the scale of interior and exterior; 5) modern advanced technology of construction, high quality modern materials, innovation at the technical building equipment.

\subsection{Social Benefits, Demanded in the Modern Society}

The development of Consumption Theory have started M. Weber (Concept of status groups), and T. Veblen (Theory of prestigious consumption). Later J. Baudrillard separated a sign-oriented consumption from the traditional consumption in the consumer society, where things are no longer in the ontological status and which 
became signs, are a marker of social status, and dress code that separates "insiders" from the "outsiders". The theoretical works of the above authors have become a kind of catechism of anti-consumerism (Baudrillard, 1998). In such a society, according to M. Weber, the unlimited need for material success, in the desire to experience the pleasure and, as a consequence, the need in the possession of not so much things, but the fact what those things represent, appears. At thus, everyone wants to consume not any benefits, but those that are important in the existing value system. Namely, that one gives a person the maximum pleasure in the world of consumerism and forms its setting to a hedonistic consumption. The fundamental quality of the global consumerism has become the attraction of social sphere in the ideology of consumption, which is used to make the value of the sphere as the signs that will encourage the consumption. Such tendency affects both mass and elitist consumption. But if in the mass consumption the thing, the possession of which raises the status of its owner, is in the focus, the elite consumption focuses not on the things, but on the social benefits, which create a completely different status levels. Such benefits include the social "lacks" (according to J. Baudrillard) - silence and peace, security, autonomy, and freedom, as well as your own space (personal, spiritual, and material). They play the role of a new differentiation in the modern society and characterize the conditions and quality of existence. According to Baudrillard, such lacks have become the new luxury items and moved to the rank of insignias and class privileges. Among them the author highlights the space and its social labeling, which is related to the location, size, condition and quality of existence in it (Baudrillard, 1998).

In the modern society we can highlight the following main benefits, emphasizing the social importance and elitism (Table 1).

Table 1. Main benefits, emphasizing the social importance and elitism

\begin{tabular}{ll}
\hline $\begin{array}{l}\text { Social benefits / "lacks" of consumer } \\
\text { society }\end{array}$ & Connotation / semantic associable \\
\hline Peace and silence & $\begin{array}{l}\text { Opportunity for a peaceful, complete detachment from the outside } \\
\text { world; recovery of sensory balance. } \\
\text { Closeness and remoteness from society. }\end{array}$ \\
Security & Isolation from the information aggression of urban environment. \\
Autonomy & Life at your own pace. \\
Time & Independence of time, things and finances. \\
Freedom & Naturalness in all aspects (life environment), resource saving. \\
Environmental friendliness & The land and all that therein is as the property. \\
Space & Freedom, autonomy, safely, peace and silence, life at your own \\
pomfort & spiritual space.
\end{tabular}

In the explanation of minimalist architectural solutions the designers are often guided by the above connotations (Table 1), connecting them with the new ideas about comfort or high quality of life (Ruby et al., 2003; Bertoni, 2002; Ferdinand, 2014).

\subsection{Minimalist Architectural Space and Its Connotations}

It is natural that any architectural object cannot exist without such term as "space", the dimensions of which we are able to assess only within certain boundaries. The walls separating the inner and outer space act as such boundaries. If the boundary "disappears" (becoming transparent), the outer and inner spaces are united among themselves visually. Thus, for example, when the outer wall "disappears" (replacement of dense materials with the glass), the visual union of inner and outer space takes place. If you remove the internal borders/walls between the rooms or replace the dense material with the transparent (for example, glass partitions), the previously dissected interior space is perceived as a single, despite the existing zoning, and, accordingly, will be appreciated as a larger and more significant one. If you use neutral colors (gray, white), bright natural colors and don't make the sharp color contrasts between the surfaces ("wall-ceiling", "wall-floor"), the space inside the room will look like it is spacious. The objects also maybe the boundary of perception, because, according to U. Eco, "men of the West perceive the space between them as the void" (Vilkovsky, 2010, p. 377). And less of them in the room, the wider, and more spacious the interior space looks like. 
All those above-mentioned techniques are used by architects when creating a minimalist space in order to focus the attention on its significance and importance.

Except the physical space that constitutes the essence of any architectural object, you can talk about the architectural object as about a unit of social space, and about its significant status. In a society built on the system of state authority, and hence the hierarchical society, there are no social spatial units that are not included in that hierarchy. In such a society it's not possible to have a social space, wherein the hierarchy and social distances are not reflected in a more or less disguised form. It also hasn't spared the modernist architecture, so, for example, in R. De Fusco you can read about the symbolic of shapes made by the Theorist of functionalism Le Corbusier (Vilkovsky, 2010).

Although, the designers themselves say about the minimalist architecture as about the out-contextual architecture, free of any ideology, about the so-called "pure" form and about "zero" architecture, but, no doubt, it's a carrier of social codes, since it's a commodity in the modern society.

The cultural substance of minimalism, being a part of the consciousness of people, who generate and reproduce it, reflects not only the world of values, it systematizes the mentality, mode and style of life. In his time W. Churchill said that "we shape our homes and then our homes shape us" (Vilkovsky, 2010, p. 130). In this context, the remark of Aureli, 90 years later, that the architecture does not just draw certain rituals, but it sets them, and in our opinion, it points to the same (Aureli, 2014). U. Eco noticed that the architect develops not only the specific functions, but first and foremost, a lifestyle and, thus, imposes it (Vilkovsky, 2010). When John Pawson was speaking of minimalist architecture, he pointed that "the architecture is the physical expression of a way of being: the form does not follow a particular fashion, it follows a particular life" (Ferdinand, 2014). Though, he stressed that minimalism is not a manifesto of Spartan life. Ilka and Andreas Ruby, by analyzing the minimalist objects, also argue that it is not a purist, but "rich" aesthetics to purify the soul, which not everyone can afford.

Bertoni allocates a small group of minimalists, which clearly formulated its position, reflecting their idea of a minimalist architectural space as the idea of vital activity of a modern human: 1)"living spaces conducive to the physical and psychological development of the individual human being", "the architectural totality simplicity as a way of life"(Ando); 2) "simplicity as a way of life" and "simplicity as a means for ordering and defining the everyday rituals" (Powson); 3)"communicative objects that are free from these superfluities"(Fronzoni); 4) "minimalism is not a style, it is an attitude, a way of being. It is a fundamental reaction to noise, visual noise, to disorder and vulgarity" (Vignelli) (Bertoni, 2002, pp. 56-57). We can state that the minimalist architectural space is considered by the designers as an object, which reflects all the things that the modern urban human needs in his daily life. Also it is presented as a carrier of ideas of a certain lifestyle. A lifestyle, which is not for everyone, but only for a narrow circle, which is free of consumerism and has the financial ability to afford it. The minimalist space is represented in this case as a "tool" by means of which the high quality of life is achievable, due to the following connotations of minimalist spatial system:

Table 2. Connotations of architectural minimalist spatial system

\begin{tabular}{ll}
\hline Architectural space & \\
Physical characteristics & Modern connotations \\
\hline Open & Freedom \\
Closed & Security, autonomy \\
Single, with the minimum zoning & Life at your own pace \\
Divided into separate spaces & Regimented, imposed a certain lifestyle \\
Large & Wealth, status (-ness) / prestige \\
Small & Asceticism, self-restraint \\
Empty & Naturalness, anti-thingism \\
Full (filled) & Artificiality, thingism \\
Ecological & Resource savings, simplicity and "naturalness" of \\
& materials. \\
\hline
\end{tabular}




\section{Conclusion}

Based on the Tables 1 and 2 we can extract the connotations related to the system of spatial organization of a minimalist space: open space-freedom; closed space - security, autonomy; single space with a minimum zoning - life at your own pace; large space — wealth, status, prestige; empty space - naturalness, anti-thingism. The environmental friendliness of minimalist space occupies a special place due to the trend for the resources saving and vigilant relationship with nature. It is expressed in the idea of creating such architectural environment, where it's possible to recover the harmony of audio-visual-tactile complex. It can be solved through the use of "natural" ("simple") materials and smooth surfaces, lack of "extra" items and spatial voids, use of modern minimization technologies and resource savings at home maintenance. The presence of maximum space and minimal zoning in the minimalist residential interiors is presented as a factor of freedom for the organization of your own life and as the life at your own pace; surface quality, its "natural" character and the emptiness of interiors - as a factor of efficiency, simplicity and countering to the consumerist culture; introversion of minimalist architecture - on the one hand, as a factor of autonomy and sensory isolation from the outside aggressive information world, and on the other hand, as a factor of security and peace, which are currently included in the concept of a new, modern comfort, reflecting the high quality of life (Ruby et al., 2003, Bertoni, 2002, Ferdinand, 2014).

When you see such architecture on the pages of glossy magazines, you want to buy such quality and this kind of comfort. But some questions remain still open: whether the above semantic associations inherent in the human consciousness coincide with things that in reality of living in those facilities gives to a person in the end? With how many simulacra will a person, who purchased the idea of a new and modern comfort and quality of life, be faced?

\section{References}

Aureli, P. V. (2014). Less is Enough: The architecture and asceticism. Moscow: Strelka Press.

Baudrillard, J. (1998). The consumer society: Myths and structures. London: SAGE.

Bertoni, F. (2002). Minimalist Architecture. Birkhäuser: Basel.

Castillo, E. (2004). Minimalism Designsource. Scranton, Penn.: Harper Design.

Frampton, K. (2007). Modern Architecture: A Critical History (4th ed.). London: Thames \& Hudson.

Grimshaw, M. (2004). Soft Modernism: The World of Post-Theoretical Designer. Retrieved from $\mathrm{http}: / / \mathrm{www} . c t h e o r y . n e t / a r t i c l e s . a s p x ? i d=418 \#$ ednref24

Glancey, J., \& Bryant, R. (1998). The New Moderns: architecture and design for living. San Francisco: Soma.

Ibelings, H. (1998). Supermodernism: Architecture in the Age of Globalisation. Rotterdam: NAI Publishers.

Jencks, Ch. (2007). Critical Modernism: Where is post-modernism doing? Great.Britain: Wiley-Academy.

Macarthur, J. (2002). The look of the object: Minimalism in art and architecture, then and now. Architectural Theory Review, 7(1), 137-148. http://dx.doi.org/10.1080/13264820209478450

Pawson, J. (1996). Minimum. Phaidon, London.

Ruby, I., Ruby, A., Sachs, A., \& Ursprung, P. (2003). Minimal Architecture. Munich: Prestel.

Stevanovic, V. (2013). A reading of interpretative models of minimalism in architecture. METU JFA, 30(2), 181-194. Retrieved from http://www.theguardian.com/culture/2004/apr/19/guesteditors1

Vilkovsky, M. (2010). Sociology of architecture. Moscow: Russkii avangard. http://archi.ru/lib/publication.html?id=1850569832\&fl=5\&sl=1

\section{Copyrights}

Copyright for this article is retained by the author(s), with first publication rights granted to the journal.

This is an open-access article distributed under the terms and conditions of the Creative Commons Attribution license (http://creativecommons.org/licenses/by/3.0/). 